\title{
Emergency obstetric hysterectomy: a lifesaving procedure
}

\section{Usha Doddamani*, Nirmala Rampure, Sanyogita Kulkarni, Shoba Patil, Neelavati Tambre}

Department of Obstetrics and Gynecology, Gulbarga Institute of Medical Sciences, Gulbarga, Karnataka, India

Received: 05 March 2018

Accepted: 03 April 2018

\section{*Correspondence:}

Dr. Usha Doddamani,

E-mail: dr.ushadoddamani@gmail.com

Copyright: (c) the author(s), publisher and licensee Medip Academy. This is an open-access article distributed under the terms of the Creative Commons Attribution Non-Commercial License, which permits unrestricted non-commercial use, distribution, and reproduction in any medium, provided the original work is properly cited.

\begin{abstract}
Background: Emergency Obstetric Hysterectomy (EOH) is removal of uterus following vaginal delivery, Emergency LSCS or within the puerperium period. Because of increasing caesarean deliveries, the number of scarred uterus is increasing exposing the gravid women to increasing morbidity from uterine rupture, placenta accrete and placenta previa thus increasing the incidence of Emergency obstetric hysterectomy. The aim was to determine the incidence, demographic details, high risk factors and fetomaternal outcome of patients who underwent EOH.

Methods: This was a retrospective study where data was collected from the record sheets of patients who underwent Emergency Obstetric Hysterectomy from January 2016 to December 2017 in the department of OBG, GIMS Gulbarga. Maternal age, parity, socioeconomic status, antenatal care, high risk factors and fetomaternal outcome were analysed.

Results: During the study period there were 17,820 deliveries out of which 20 cases underwent EOH giving an incidence of $0.12 \%$. Most of patients were uneducated, unbooked, low SES and of rural background and were multiparous. Main cause for EOH were rupture uterus, PPH and morbidly adherent placenta. There were 2 cases of maternal mortality and fetal mortality was $65 \%$.

Conclusions: Though EOH is a lifesaving procedure it curtails the reproductive capacity of the women. Proper antenatal care, early referral, timely decision and skill of surgeon in performing this procedure is important.
\end{abstract}

Keywords: Emergency obstetric hysterectomy (EOH), Morbidly adherent placenta, PPH, Rupture uterus

\section{INTRODUCTION}

Emergency Obstetric Hysterectomy (EOH) is defined as extirpation of uterus either at the time of caesarean section or following vaginal delivery or within the puerperium period. It is usually performed in the face of unrelenting and life threatening obstetric haemorrhage. A near miss event is defined as a woman who nearly died but survived a complication that occurred during pregnancy, childbirth, or within 42 days of termination of pregnancy. ${ }^{1}$ Although EOH saves the life of the mother but at the same time it curtails the reproductive capacity of the mother.
In developing countries, the most common indication is PPH when conservative measures fail and rupture uterus when other measure to control bleeding fails. ${ }^{2}$ As the number of caesarean section is increasing, the number of scarred uterus is also increasing. This exposes the gravid women to increasing morbidity from uterine rupture, placenta previa and placenta accrete thus increasing the incidence of EOH. ${ }^{3,4}$

EOH is more common in developing countries like ours because of high incidence of unbooked and improperly supervised deliveries outside the hospital. The delay in presentation to the hospital makes EOH to be associated with high fetomaternal morbidity and mortality. ${ }^{5}$ 
Many times, it is difficult decision and require good clinical judgement. Most of the time the operation is carried out when the patient's condition is too critical to withstand the risk of anesthesia or surgery. Proper timing and meticulous care may reduce or prevent maternal complications.

\section{METHODS}

We retrospectively analyzed a total of 20 women who underwent Emergency obstetric hysterectomy between January 2016 to December 2017 in the department of OBG GIMS Gulbarga. All booked or unbooked patients who underwent emergency obstetric hysterectomy at the time of pregnancy, delivery, caesarean section or during puerperium were included in the study. The study also included hysterectomies done for complications following pregnancy termination such as perforation. Some obstetric hysterectomy was also done for fibroid uterus resulting in postpartum haemorrhage. Women undergoing hysterectomy for indication other than obstetrics or after 42 days of delivery were excluded from the study.

The data was collected from hospital records. The medical records sheets of all identified women were reviewed regarding age, parity, antenatal booking status, high risk factors, indication for $\mathrm{EOH}$ and fetomaternal morbidity and mortality. Data was collected on a proforma and entered into computer using SPSS version 10 for analysis.

Permission of the institutional ethical committee was obtained before recording data on proforma with the assurance of its confidentiality.

The data was collected from hospital records. All women who underwent EOH during pregnancy, delivery, puerperium were included. The study also included hysterectomy done for induced abortion or had perforation during evacuation.

The medical records sheets of all identified women were reviewed regarding parity, antenatal booking status, high risk factors, indication for $\mathrm{EOH}$ and fetomaternal complications.

\section{RESULTS}

There were 17,820 deliveries during the study period from JAN 2016 to DEC 2017. Out of these 6,942 had caesarean section while 10,874 delivered vaginally. EOH were performed in 20 cases. The incidence of EOH was $0.12 \%$.

Majority of patients belonged to age group 20-25 yrs $(55 \%)$. Maximum age was 39 yrs and minimum age was 22years. Most of them were multiparous, uneducated and of rural background. $65 \%$ of them were unbooked. $60 \%$ were referred cases as our hospital being a referral centre
Table1. The most common indication for $\mathrm{EOH}$ in our study was rupture uterus (35\%) followed by PPH (30\%) and morbidly adherent placenta $(20 \%)$. Only one patient underwent $\mathrm{EOH}$ due to perforation of uterus following MTP.

There was one case of uterine inversion. All patients who underwent $\mathrm{EOH}$ have one or more high risk factors like previous LSCS, APH, grand multipara, fibroid uterus, morbidly adherent placenta and obstructed labour.

Table 1: Demographic profile of cases

\begin{tabular}{|lc|c|}
\hline Variable & No. of patients & $\%$ \\
\hline Age & & \\
\hline $21-25$ & 11 & 55 \\
\hline $26-30$ & 6 & 30 \\
\hline $31-35$ & 2 & 10 \\
\hline $35-40$ & 1 & 5 \\
\hline Parity & & \\
\hline 1 & 3 & 15 \\
\hline 2 & 6 & 30 \\
\hline 3 & 3 & 15 \\
\hline$>3$ & 8 & 40 \\
\hline Booking status & & \\
\hline Booked & 7 & 35 \\
\hline Unbooked & 13 & 65 \\
\hline Residence & & 70 \\
\hline Rural & 14 & 30 \\
\hline Urban & 6 & \\
\hline
\end{tabular}

Maternal morbidity in the form of various complications were encountered including febrile morbidity, bladder injury, wound infections, coagulopathy and haemorrhagic shock.

There were 2 maternal deaths, one was due to uterine inversion with shock and the other one was due to atonic PPH with DIC. All our patients required blood transfusion and ICU monitoring. Fetal mortality was seen in $65 \%$ of cases.

\section{DISCUSSION}

Emergency obstetric hysterectomy remains a necessary tool to save the lives of women during catastrophic rupture of uterus and intractable PPH. First caesarean hysterectomy was performed by Strorer in United States in $1869 .^{6}$

Despite regular availability of contraceptives and abortion services and reduced family size world over, there has been consistent rise in the rates of caesarean attributable in the part, to the patient preferences and medicolegal implications on medical fraternity.

In addition to it advances in anaesthesia, intensive care back up, availability of blood bank has made it a safer and painless alternative to labour. 
This has not only given rise to complications like abnormal placentation and uterine rupture but also the incidence of PPH, giving obstetric hysterectomy more relevance in present day modern obstetric practice. ${ }^{7}$

Incidence of $\mathrm{EOH}$ in our study was $0.12 \%$ which was comparable to reported incidence of $\mathrm{EOH}$ in other studies. (Table 2)..$^{8-12}$

Table 2: Incidence of emergency obstetric hysterectomy by different authors.

\begin{tabular}{|l|l|}
\hline Studies & Incidence (\%) \\
\hline Mukherjee et al & 0.15 \\
\hline Forna F et al & 0.08 \\
\hline Ahmad and Mir et al & 0.26 \\
\hline Kant and Wadhwani et al & 0.26 \\
\hline Shirodkar et al & 0.16 \\
\hline
\end{tabular}

Most of these women were unbooked cases belonging to the low SES resulting from neglected obstetric care and delayed transport. In our study $65 \%$ of them belonged to unbooked group. This was almost similar to $69.9 \%$ reported by Sinha and $69.7 \%$ reported by Gupta. ${ }^{13,14}$

Rupture uterus was the commonest indication for emergency obstetric hysterectomy in our series accounting for $35 \%$ followed by atonic PPH accounting for $30 \%$. Our results are comparable to other studies (Table 3). ${ }^{15-18}$

Table 3: Indications of Emergency obstetric hysterectomy by different authors.

\begin{tabular}{|llll|}
\hline Authors & $\begin{array}{l}\text { Rupture } \\
\text { uterus }\end{array}$ & $\begin{array}{l}\text { Atonic } \\
\text { PPH }\end{array}$ & $\begin{array}{l}\text { Placenta } \\
\text { accrete }\end{array}$ \\
\hline Sahu et al & 38.88 & 27.70 & 13.88 \\
\hline Khan et al & 34.86 & 29.81 & 8.71 \\
\hline Singh et al & 59.04 & 18.09 & 14.28 \\
\hline Mukherjee et al & 45.45 & - & 30.30 \\
\hline Present study & 35 & 30 & 20 \\
\hline
\end{tabular}

Febrile morbidity was the most common maternal complication seen in $30 \%$ of cases which was comparable to Jadhav et al., and Bushra et al., The other complications were wound infection, bladder injury and haemorrhagic shock. ${ }^{16,19}$ Maternal mortality was seen 2 cases accounting to $10 \%$ which was comparable to studies conducted by Shaik $\mathrm{N}$ et al., who reported 12.19 $\%$ and Temizkhan et al., reported $8.6 \%$ and Bhawna Sharma et al., reported $13.3 \%$ of maternal mortality.,20,21

\section{CONCLUSION}

Emergency obstetric hysterectomy is a lifesaving procedure. Every obstetrician should be trained to perform this procedure. Timely decision to perform EOH can be the difference between the life and death of a women. Proper antenatal care, delivery by trained personnel, active management of labour, early recognition of complications, timely referral of high risk to higher centre, easy availability of transport and blood transfusion facilities are all needed to improve the maternal health of our country.

\section{ACKNOWLEDGMENTS}

Authors acknowledge all their colleagues of Department of OBG for supporting them in conducting the study and also the clerical staff in preparing the article.

\section{Funding: No funding sources}

Conflict of interest: None declared

Ethical approval: The study was approved by the Institutional Ethics Committee

\section{REFERENCES}

1. Say L, Souza JP, Pattinson RC. WHO working group on Maternal Mortality and Morbidity classifications. Maternal near miss towards a standard tool for monitoring quality of maternal health care. Best Pract Res Clin Obstet Gynaecol. 2009;23:287-96

2. Najam R, Bansal P, Sharma R, Agrawal D. Emergency Obstetric Hysterectomy: A retrospective study at a tertiary care hospital. J Clinic Diagn Res. 2010;4:2864-8.

3. Korejo R, Bhutta S, Nasir A, Yasmin H. Emergency Obstetric Hysterectomy. JPMA. 2012;62:1322-25.

4. Zelop CM, Harlow BL, Frigoletto FD, Safon LE, Saltzman Dh. Emergency Peripartum Hysterectomy. Am J Obstet Gynecol. 1993;168:1443-5.

5. Udoma E, John M, Etuk S, Ekanem A. Mortality in Calabar, Nigeria. Nig J Med Pract. 2003;66:52-5.

6. Allahbadia GV, Vaidya P. Obstetric Hysterectomy ( A review of 50 cases from January 1987 to august 1990) J Obstet Gynecol Ind. 1991;41:634-7.

7. Sharma B, Saxena N, Gupta V . A retrospective study of obstetric hysterectomy inA tertiary care centre for a period of 5 years. Int $\mathrm{J}$ Reprod Contracept Obstet Gynecol. 2016;5:3778-81.

8. Mukerjee P, Mukerjee G, Das C. Obstetric hysterectomy- A review of 107 cases. J Obstet Gynecol India. 2002;52:34-6.

9. Forna F, Miles AM, Jamieson DJ. Emergency peripartum hysterectomy: a Comparison of caesarean and postpartum hysterectomy. Am J Obstet Gynecol. 2004;190:1440-4.

10. Ahmad SN, Mir IH. Emergency Peripartum Hysterectomy: Experience at apex hospital of Kashmir Valley. Int J Gynaecol Obstet. 2007;8:2.

11. Kant A, Wadhwani k. Emergency obstetric hysterectomy. J Obstet Gynecol India. 2005;55:1324.

12. Shirodker SD, Pandey A, Yadav S. Emergency Obstetric Hysterectomy: review at a Tertiary care hospital. Int J Reprod Contracept Obstet Gynecol. 2016;5:3811-4. 
13. Sinha HH, Mishra MG. Hysterectomy for obstetric emergencies. J Obstet Gynecol India. 2001;51:111-4.

14. Gupta S, Dave A, Bandi G. Obstetric hysterectomy in modern day obstetrics: A review of 175 cases over a period of 11 years. J Obstet Gynecol India. 2001;51:91-3.

15. Sahu L, Chakraverty B, Panda S. Hysterectomy for obstetrics emergencies. J Obstet Gynecol India. 2004;54:34-6.

16. Khan Bushra, Khan Baynazir, Sultana R, Bashir R, Deeba F. A ten-year review of Emergency peripartum hysterectomy in a tertiary care hospital. J Ayub Med Coll Abottabad. 2012;24:14-7.

17. Singh N, Pandey K, Gupt R, Agarwal S, Choudary A. Obstetric hysterectomy, still a lifesaving tool in modern day obstetrics: a five-year study. Int J Reprod Contracept Obstet Gynecol. 2014;3:540-3.
18. Surya M, Khushpreet K, Parneet K. Obstetric Hysterectomy: Aray of hope for a dying mother. Indian J of Obstet Gynecol Res. 2017;4:83-5.

19. Jadhav SN, Nanda S, Panchal G, Desai MR. Study of Emergency Obstetric Hysterectomy. International J Scien Res. 2014;3:341-2.

20. Shaik N, Shaik S, Shaik J. Morbidity and Mortality associated with obstetric hysterectomy. J Ayub Med Coll Abottabad. 2010;22:100-4.

21. Temizkhan O, Angin D, Karakus R. Changing trends in emergency peripartum hysterectomy in a tertiary obstetric centre in Turkey during 2000-2013. J Turk Ger Gynecol Assoc. 2016;17:26.

Cite this article as: Doddamani U, Rampure N, Kulkarni S, Patil S, Tambre N. Emergency obstetric hysterectomy: a lifesaving procedure. Int J Reprod Contracept Obstet Gynecol 2018;7:1876-9. 